\title{
Population and distribution of wild Asian elephants (Elephas maximus) in Phu Khieo Wildlife Sanctuary, Thailand
}

\author{
Nyi Nyi Phyo Htet ${ }^{1}$, Rattanawat Chaiyarat ${ }^{\text {Corresp., }}{ }^{2}$, Nikorn Thongthip ${ }^{3}$, Panat Anuracpreeda ${ }^{4}$, Namphung Youngpoy \\ ${ }^{2}$, Phonlugsamee Chompoopong ${ }^{5}$ \\ 1 Faculty of Environment and Resource Studies, Mahidol University, Salaya, Nakhon Pathom Province, Thailand \\ 2 Wildlife and Plant Research Center, Faculty of Environment and Resource Studies, Mahidol University, Salaya, Nakhon Pathom Province, Thailand \\ 3 Faculty of Veterinary Medicine, Kasetsart University, Kampang Saen, Nakhon Pathom Province, Thailand \\ ${ }^{4}$ Institute of Molecular Biosciences, Mahidol University, Salaya, Nakhon Pathom Province, Thailand \\ 5 Phu Khieo Wildlife Sanctuary, Department of National Parks, Wildlife and Plant Conservation, Khon San District, Chaiyaphum Province, Thailand \\ Corresponding Author: Rattanawat Chaiyarat \\ Email address: rattanawat.cha@mahidol.ac.th
}

Background. The populations of wild Asian elephants (Elephas maximus) have increased recently after a period of worldwide decline in protected areas. It is important to understand the dynamics and distribution of the remaining populations to ensure their conservation and prevent human-elephant conflicts. Methods. We monitored the population distribution of elephants between 2016 and 2019 in the Phu Khieo Wildlife Sanctuary, Thailand. We set one hundred forty-nine camera trap locations; cameras recorded 38,834 photos over 6,896 trap nights. Elephants were captured in 4,319 photographs. The maximum entropy modeling software MaxEnt was used to identify elephants' habitat preferences within 49 of the 149 total camera trap locations according to five environmental factors. Results. One hundred fourteen elephants were identified. We identified 30 adult males, 43 adult females, 14 sub-adult males, nine sub-adult females, 11 juveniles, and seven calves. The age structure ratio based on adult females was $0.7: 1: 0.3: 0.2: 0.3: 0.2$, and the ratio of reproductive ability between adult females, juveniles, and calves was 1:0.2:0.1. A suitable elephant habitat was determined to be $1,288.9 \mathrm{~km}^{2}$ using Area Under the Curve (AUC). An AUC $=0.061$ indicated good performance. Our model classified habitat preferences associated with elevation, forests, salt licks, human activity, and slope. Conclusions. According to our probability map this sanctuary can provide a suitable habitat for elephants. Our results indicate that effective management practices can protect wild Asian elephants in the region and reduce conflict between humans and elephants. 
1 Population and distribution of wild Asian elephants 2 (Elephas maximus) in Phu Khieo Wildlife Sanctuary, 3 Thailand

4

Nyi Nyi Phyo Htet ${ }^{1}$, Rattanawat Chaiyarat ${ }^{2, *}$, Nikorn Thongthip ${ }^{3}$, Panat Anuracpreeda ${ }^{4}$, Namphung Youngpoy ${ }^{2}$, Phonlugsamee Chompoopong ${ }^{5}$

${ }^{1}$ Master of Science Program in Environmental Management and Technology (International Program) Faculty of Environment and Resource Studies, Mahidol University, Nakhon Pathom Province, Thailand

${ }^{2}$ Wildlife and Plants Research Center, Faculty of Environment and Resource Studies, Mahidol University, Nakhon Pathom Province, Thailand

${ }^{3}$ Faculty of Veterinary Medicine, Kasetsart University, Kampang Saen, Nakhon Pathom Province, Thailand

${ }^{4}$ Institute of Molecular Biosciences, Mahidol University, Nakhon Pathom Province, Thailand ${ }^{5}$ Phu Khieo Wildlife Sanctuary, Department of National Parks, Wildlife and Plant Conservation, Khon San District, Chaiyaphum Province, Thailand

Corresponding Author:

Rattanawat Chaiyarat ${ }^{1}$

Faculty of Environment and Resource Studies, Mahidol University, Phutthamonthon 4 Road, Salaya, Phutthamonthon District, Nakhon Pathom Province, 73170, Thailand, Email address: rattanawat.cha@mahidol.ac.th

\begin{abstract}
Background. The populations of wild Asian elephants (Elephas maximus) have increased recently after a period of worldwide decline in protected areas. It is important to understand the dynamics and distribution of the remaining populations to ensure their conservation and prevent human-elephant conflicts. Methods. We monitored the population distribution of elephants between 2016 and 2019 in the Phu Khieo Wildlife Sanctuary, Thailand. We set one hundred forty-nine camera trap locations; cameras recorded 38,834 photos over 6,896 trap nights. Elephants were captured in 4,319 photographs. The maximum entropy modeling software MaxEnt was used to identify elephants' habitat preferences within 49 of the 149 total camera trap locations according to five environmental factors. Results. One hundred fourteen elephants were identified. We identified 30 adult males, 43 adult females, 14 sub-adult males, nine subadult females, 11 juveniles, and seven calves. The age structure ratio based on adult females was $0.7: 1: 0.3: 0.2: 0.3: 0.2$, and the ratio of reproductive ability between adult females, juveniles, and calves was 1:0.2:0.1. A suitable elephant habitat was determined to be $1,288.9 \mathrm{~km}^{2}$ using Area Under the Curve (AUC). An AUC $=0.061$ indicated good performance. Our model classified habitat preferences associated with elevation, forests, salt licks, human activity, and slope. Conclusions. According to our probability map this sanctuary can provide a suitable habitat for elephants. Our results indicate that effective management practices can protect wild Asian elephants in the region and reduce conflict between humans and elephants.
\end{abstract}


44

45

46

47

48

49

50

51

52

53

54

55

56

57

58

59

60

61

62

63

64

65

66

67

68

69

70

71

72

73

74

75

76

77

78

79

80

81

82

83

84

85

\section{Introduction}

Wild Asian elephants (Elephas maximus) are the largest living terrestrial mammals in Asia. Wild elephants play a crucial role in forest ecosystem by opening up forests and distributing the seeds of trees and shrubs from one place to another. Because of this they are commonly referred to as an umbrella species (Tan et al., 2021). Asian elephants are found in grasslands, tropical evergreen forests, semi-evergreen forests, moist deciduous forests, and dry deciduous forests in 13 countries (Choudhury, 1999). In the past, habitat loss was a primary factor in the decline of the species. As the human population in the region has increased, vast areas of this elephant's forest habitat were logged or converted for agriculture. This isolated elephants in habitat patches as ancient migratory routes were cut off (Acharya et al., 2016). Wild Asian elephant populations are also threatened by ivory and game hunters (Vigne, 2013; Prakash et al. 2020). Consequently, between 2003 and 2020, this elephant population declined from an estimated 41,410-52,345 individuals (Sukumar, 2003) to approximately 4,189-6,999 individuals (Williams et al., 2020). According to the International Union for Conservation of Nature (IUCN) red list, the wild elephant is endangered in each country worldwide (IUCN, 2020).

In Thailand, wild Asian elephants are spread across protected areas, mainly in the mountains along the border with Myanmar. Elephants are also found in smaller fragmented populations in the southern peninsula; several forest complexes on the border with Malaysia; to the east in a forest complex made up of the Khao Ang Runai Wildlife Sanctuary, Khao Soi Dao Wildlife Sanctuary, Khao Khitchakut National Park, and Khao Cha Mao National Park; and to the northeast at the Dong Phaya Yen-Khao Yai Forest Complex, which includes Khao Yai National Park, and the Western Isaan Complex. The degradation and fragmentation of elephant habitats are the biggest threat to Thailand (Suksavate etal., 2019) as these increase conflicts between humans and elephants (Van de Water and Matteson, 2018). The population of wild elephants in Thailand in 2020 is made up of only approximately 3,126 to 3,341 individuals (Williams et al., 2020).

Elephants' habitats are fragmented in the protected areas, but they also include agricultural areas, which increase human-elephant conflicts near the sanctuary (Chaiyarat et al., 2015). It is important to understand the distribution and dynamics of the remaining populations to ensure effective conservation practices and prevent conflict.

\section{Materials \& Methods}

Study area

Our study was conducted from 2016 to 2019 in the Phu Khieo Wildlife Sanctuary (PKWS) which spans over $1,560 \mathrm{~km}^{2}$ in the Chaiyaphum Province of Thailand (latitude $16^{\circ} 5^{\prime}$ and $16^{\circ} 35^{\prime} \mathrm{N}$ and longitude $101^{\circ} 20^{\prime}$ and $101^{\circ} 55^{\prime} \mathrm{E}$ ) (Fig. 1). Eight connecting protected areas cover more than $4,594 \mathrm{~km}^{2}$ in the Western Issan Forest Complex. The sanctuary is near three other protected areas: the Nam Nao National Park to the north, Tat Mok National Park to the west, and Ta Bao-Huai Yai Wildlife Sanctuary to the southwest. The annual rain fall is 1,368 mm per year, and the average temperature is approximately $18{ }^{\circ} \mathrm{C}$ to $27{ }^{\circ} \mathrm{C}$. The average elevation is $900 \mathrm{~m}$ (min. $200 \mathrm{~m}$ to max. 1,300 m) above the average sea level (ASL). Dry evergreen forests cover approximately $68 \%$ of the area. Of this total area, $27 \%$ are mixed deciduous forests 
86 dominating the low lands, $4 \%$ are dry dipterocarp forests, $0.6 \%$ are pine forests, and $0.4 \%$ area

87

88

89

90

91

92

93

94

95

96

97

98

99

100

101

102

103

104

105

106

107

108

109

110

111

112

113

114

115

116

117

118

119

120

121

122

123

124

125

126

secondary forest (Faculty of Forestry, 2010).

\section{Camera Trap Survey}

Global Positioning System (GPS) coordinate information was collected from camera trap placements in the field. The environmental conditions were the same ones recorded by Pearce $\&$ Boyce (2006). A set of environmental factors that likely model a species' environmental requirements was obtained from a set of occurrence localities, influencing the suitability of the environment for the species (Phillips, 2017). Seven environmental factors were combined with the five predicted factors to generate the model. These were: human activity (road, stream, wildlife guard station, and villages), forest types, salt licks, elevation, and slope. As previously reported in Chaiyarat et al. (2019), environmental parameters generated from available Geographic Information System (GIS) layers and habitat composition was analyzed using the land-use layers of the Phu Khieo Wildlife Sanctuary digital map. Topography data was obtained from a digital elevation model (DEM) generated by the Phu Khieo Wildlife Sanctuary (2006) from 1:50,000 topographic maps. A DEM was used to generate the slope and then images were resampled to a 30-m pixel resolution (Fig. 2). These parameters were used to estimate the distance between parameters in each pixel and each elephant observation point. A model built using 49 camera sites captured wild Asian elephants in 4,319 photographs. The other 100 camera trap stations were considered pseudo-absent from the total 149 camera trap stations, which captured 38,834 photographs. Images were captured using MaxEnt set to a 25 random test percentage with 15 replicates (more than the sample size) and 5,000 maximum iterations.

We used the HCO SG565 flash camera-traps (HCO Outdoor Products, Norcross, Georgia, $U S A$ ) to obtain photographs of individual elephants. Fifteen camera trap stations systematically were set up in $3 \times 3 \mathrm{~km}^{2}$ grid cells within 3 months of sampling blocks. Two camera traps were used per grid with $10 \mathrm{~m}$ apart from each other. The camera traps operated continually for 24 hours a day, recording the date and time of each photograph. The batteries were changed in the camera traps monthly, and the SD card data was transferred to HD data storage. Camera traps were attached to trees approximately $0.75 \mathrm{~m}$ from the ground (Rowcliffe et al., 2008) with a view range of at least five $\mathrm{m}$ to six meters to capture a single wild elephant up to $20 \mathrm{~m}$ away to allow for a complete view of a wild elephant herd (Varma et al., 2006).

Relative frequency and relative abundance index

The correlation structure of the set of environmental factors (salt lick, wildlife sanctuary guard station, stream, village, road, elevation, and slope) using a matrix of Kendall's rank correlation coefficients, $\tau$ (Kendall, 1938; Halvorsen et al., 2016) presented by Chaiyarat et al. (2019) were used to test the autocorrelation among each environmental factor. Relative frequency (RF) was used to estimate the distribution of the wild Asian elephants, and the relative abundance index (RAI) was used to estimate the abundance of the wild Asian elephants.

Population survey

Peer) reviewing PDF | (2021:01:57278:3:0:NEW 6 Jul 2021) 
Photographs were used to identify and record the location, date, and time of wild elephant sightings. A score of 0 indicated bad image quality and the photograph was discarded. A score of 5-10 indicated that the picture quality was sufficient to identify individual herd characteristics. Photographs' ratings were based on their quality, clarity, and the position of the elephants in the frame (Varma et al., 2006; 2012). A rating of five or above would allow us to determine whether elephants were individual adult males, females, sub-adult males, females, juveniles, or calves (Arivazhagan and Sukumar, 2008). We recorded elephants' clear morphological distinguishing features and basic body measurements to help identify individuals (Goswami et al., 2012; Vidya et al., 2014) (Supplementary S1). Photos were used to identify individual elephants and unique herds. We conducted a census of individual adult males (AM) and adult females (AF), sub-adult males (SM), sub-adult females (SF), juveniles (JU), and calves (CA) for each herd. Herd density was calculated using crude density.

Herd distribution and distribution model

We used camera traps (Aebischer et al., 1993) to obtain statistically independent wild Asian elephant distribution data. Photographs taken by our traps were used to identify each herd. The location of each herd was used to predict distribution patterns and population habitat with MaxEnt. We only used MaxEnt with species records when individuals were either present, pseudo-absent, or truly absent at any given point on the landscape within a given time frame (Pearce and Boyce, 2006).

We used the jackknife procedure and percentage factor contributions to estimate the relative influence of different predictive factors in MaxEnt. Model performance was evaluated using the area under the receiver-operating characteristic (ROC) curve (AUC) (Fielding and Bell, 1997) as previously reported in Chaiyarat et al. (2019).

Population home range

Wild Asian elephants are a herd animal; therefore, we grouped their home ranges for our study. In Chaiyarat et al. (2015, 2019) we used the kernel density-estimate (KDE) bounds on the innermost $95 \%$ of the 49 presence data points to estimate habitat areas (Seaman et al., 1999). The model derived from this equation was used to create a habitat use map in ArcGIS 9.3 (Environmental Systems Research Institute; ESRI, 2007).

Statistical analysis

The RF was calculated for all camera trap locations as previously described in Chaiyarat et al. (2015):

$\mathrm{RF}=$ No. camera locations that captured photographs $\times 100 /$ total camera locations

The RAI calculated for all camera trap locations as:

RAI $=$ No. of detections for wild Asian elephants $\times 100$ total number of camera trap nights 
167

168

169

170

171

172

173

174

175

176

177

178

179

180

181

182

183

184

185

186

187

188

189

190

191

192

193

194

195

196

197

198

199

200

201

202

203

204

205

206

207

Wild Asian elephant detection was considered to be independent if the time between consecutive photographs of the same individual was more than 0.5 hours apart. This definition follows O'Brien et al. (2003).

The crude density (D) was calculated as:

$\mathrm{D}=$ Total number of wild Asian elephants/total number of Phu Khieo Wildlife Sanctuary

The habitat suitability area ranged from 0 (completely unsuitable habitat) to 1 (optimal habitat). Suitable habitats were classified into three categories:

Most suitable $=$ most optimal habitat for wild Asian elephants $>0.66$ to 1

Moderate suitable $=$ moderate optimal habitat for wild Asian elephants $>0.33$ to 0.66

Lowest suitable $=$ low optimal habitat for wild Asian elephants $>0$ to 0.33

In Chaiyarat et al. (2019) we used MaxEnt to calculate the AUC value in a slightly different manner (Phillips, 2017): an AUC value of 0.5 indicated that the model did not perform better than a random model, whereas a value of 1 indicated perfect discrimination (Swets, 1988).

A one-way ANOVA was used to compare the population structure in different areas. The correlation coefficient was used to analyze the relationship between population structure and water sources, natural licks, elevation, slope, and forest types. We used SPSS as previously described in Chaiyarat et al. (2015). Environmental factors affecting population structure were considered to be significant at $\mathrm{p}<0.05$. This work was conducted under an appropriate animal ethics approval (COA. No. MU-IACUC 2016/17) with permission from the Department of National Parks, Wildlife, and Plant Conservation (NRCT No. 0402/3908).

\section{Results}

Autocorrelation test

The correlation structure for seven environmental factors (station and stream, station and village, station and elevation, village and elevation, salt lick and road, and road and slope) had a very strong positive correlation. In contrast, there was a negative correlation between two factors (stream and village; stream and elevation; $\mathrm{t}=0.192$ ) that was very statistically significant $(\mathrm{p}<$ 0.001) (Table 1). These environmental factors helped determine the distribution models.

Relative frequency and relative abundance index

The RF was $32.9 \%$ for all camera trap stations and the RAI of wild Asian elephants in the PKWS was 62.6 captures per 100 trap nights (Table 2).

\section{Population survey}

A total of 114 wild Asian elephants were identified from 4,319 photographs taken at 49 camera trap stations in the PKWS (Table 2). The crude density of wild Asian elephants in the sanctuary was 0.07 individuals per $\mathrm{km}^{2}$. The population consisted of 30 adult males, 43 adult females, 14 sub-adult males, nine sub-adult females, 11 juveniles, and seven calves, with the population ratio was $0.7: 0.1: 0.3: 0.2: 0.3: 0.2$. The ratio of reproductive ability between adult females

Peer) reviewing PDF | (2021:01:57278:3:0:NEW 6 Jul 2021) 
208 (including sub-adult females), juveniles, and calves was 1.0:0.2:0.1 $(\mathrm{F}=1.072, \mathrm{df}=5, \mathrm{p}=0.382$ )

209 (Table 3).

210

211

212

213

214

215

216

217

218

219

220

221

222

223

224

225

226

227

228

229

230

231

232

233

234

235

236

237

238

239

240

241

242

243

244

245

246

247

248

Herd distribution

Wild Asian elephants were separated into seven herds based on individual classifications (Fig. 3). Herds 1-5, roamed in the northwestern part of the sanctuary, while the other two preferred the eastern (herd 6), or western regions (herd 7).

\section{Distribution model}

We used MaxEnt to calculate the habitat model of the wild Asian elephants as previously described in Chaiyarat et al. (2019). Our results revealed that all 15 models generated training or testing models when compared with a random model where the average AUC was $0.61 \pm 0.13$. The test AUC values were lower than the training AUC values (Fig. 4A, B). The average training AUC values were 0.689 , while the test AUC values ranged from 0.393 to 0.819 . The model was run 15 times (Table 4). The contribution of the environmental factors and the results of the jackknife test analysis are presented in Fig. 4C. Analysis of the environmental factors independently indicated that distance from salt licks, elevations, land covers, and forest types were more important than slopes. The distance from salt licks was the most important predictor (36.4\%) of habitat suitability. The second and third most important factors were elevation (23.5\%) and human activities (20.2\%), respectively. The contribution of environmental factors (Table 4) and response curves (Fig. 5) showed that the main environmental factors affecting habitat suitability were elevation (52\%), forest types (23.2\%), and distance from the salt licks (14.9\%). Using the MaxEnt habitat model, we determined that species' suitable area was $1,288.9 \mathrm{~km}^{2} ; 276.9 \mathrm{~km}^{2}$ was found to be unsuitable (Table 5). Highly and moderately suitable areas were 672.3 and $616.6 \mathrm{~km}^{2}$, respectively. Most elephant herds were situated between 700-900 m above average sea level (ASL) and found in dry evergreen forests. However, most solitary males and a herd of males were found 400-700 m above the PKWS. The MaxEnt habitat model was similar to the minimum convex polygon (MCP) and $95 \%$ KDE. The model showed that wild Asian elephants used a wide range of habitats (Table 5 and Fig. 6). The total area of $95 \%$ of the MCP was $1,098 \mathrm{~km}^{2}$. The whole area inside the PKWS using $95 \%$ of the KDE was $1,554.9 \mathrm{~km}^{2}$.

Population home range

The population of herd 3 was the largest of the seven female herds at $72 \mathrm{~km}^{2}$ (Table 5 and Fig. 3D). The second largest was herd 2 at $67.5 \mathrm{~km}^{2}$ (Fig. 3C). The smallest was herd 7 at only 4.5 $\mathrm{km}^{2}$ (Fig. 3H).

\section{Discussion}

The Asian elephant population in this sanctuary currently has 114 elephants; in our previous study (Chaiyarat et al., 2015) there were at least 181 elephants. The number of elephants was obtained using camera trap analysis in the Salakphra Wildlife Sanctuary, Thailand. In this study, the RAI was higher than that of the Salakphra Wildlife Sanctuary (Chaiyarat et al., 
249 2015). The elephant density found in these studies $\left(0.07\right.$ individuals per $\left.\mathrm{km}^{2}\right)$ was the lowest when 250 compared to the Huai Kha Khaeng Wildlife Sanctuary (0.7 individuals per $\mathrm{km}^{2}$ ) (Sukmasuang 251 2003), the Khao Ang Rue Nai Wildlife Sanctuary (0.1 individuals per $\mathrm{km}^{2}$ ) (Wanghongsa et al.,

252 2006), and the Salakphra Wildlife Sanctuary in Thailand $\left(0.21\right.$ individuals per $\left.\mathrm{km}^{2}\right)($ Chaiyarat et 253 al., 2015). It was also lower than the Bardia National Park in Nepal (0.2 individuals per km²) 254 (Flagstad et al., 2012). According to Sukumar and Santipiallai (1993)'s carrying capacity model, 255 wild Asian elephant density may reach 0.2 to 0.3 individual per $\mathrm{km}^{2}$ or 312 to 468 individuals in

256

257

258

259

260

261

262

263

264

265

266

267

268

269

270

271

272

273

274

275

276

277

278

279

280

281

282

283

284

285

286

287

288

289 the PKWS. This may be the reason that elephants remain inside the sanctuary when compared to other protected areas (Chaiyarat et al., 2015): their population is at $36.5 \%$, the lowest carrying capacity range described by Wanghongsa et al. (2007). During our study, there was no immigration or emigration.

The population structure in the area was comprised of mostly adults, as previously described in Chaiyarat et al. (2015). Obtaining this information was only possible due to camera traps identifying the individuals and classifying their age and sex (Varma et al., 2006). The population also consisted of more adult females than adult males and there were high reproduction rates. Overall, however, the reproductive ratio of wild Asian elephants in the PKWS was relatively low compared to the findings of Katugaha et al. (1999) in Ruhuna National Park, Sri Lanka, Choudhury (1999) and Ramesh et al. (2012) in India, and Chaiyarat et al. (2015) in the Salakphra Wildlife Sanctuary, Thailand. In our study larger herds tended to have a higher reproductive ratio when compared to smaller ones, such as herd 7, and may be why the total population in our study was the lowest when compared with others. The variability in population dynamics likely reflects differences in environmental conditions and carrying capacities between sites as previously described in Ramesh et al. (2012) and Chaiyarat et al. (2015). These conditions include elevation, land covers, and salt licks in the PKWS. We found that the elephant population is increasing in PKWS as previously described in Chaiyarat et al. (2015) in the Salakphra Wildlife Sanctuary.

In Indonesia, the Sumatran elephants preferred lower elevation $(<200 \mathrm{~m})$ and slopes between 0 to 20\% (Wilson, et al., 2021). Our study found that wild Asian elephants preferred higher elevations, while another suggested that wild Asian elephants generally avoid feeding or walking in upland areas to save energy (Wall et al., 2006). Elephants in the PKWS are found at high elevations as the sanctuary is located on the plateau and flat plains on the top of the mountain, with deep slopes along the boarder (Faculty of Forestry, 2010). Conversely, solitary male elephants appeared at higher elevations in dry evergreen forests to avoid conflict with the dominant males in the lowland areas (Chaiyarat et al., 2015). This finding is similar to that of Steinmetz et al. (2008), who found elephants in the hilly evergreen forests above 1,000 $\mathrm{m}$ in the Thung Yai Naresuan Wildlife Sanctuary, Thailand. Wanghongsa et al. (2006) and Joshi (2009) documented elephants in areas up to 1,300 m ASL. Wild Asian elephants in the PKWS mainly used shallow slopes $(0-20 \%)$, which is consistent with our previous research (Chaiyarat et al., 2015). We also found that elephants also used flat plains, which is consistent with the results of other studies (Alfred et al., 2012; Chaiyarat et al., 2015). Waterholes are not a prominent environmental factor in the PKWS (Alfred et al., 2012; Chaiyarat et al., 2015) as water can be 
290

291

292

293

294

295

296

297

298

299

300

301

302

303

304

305

306

307

308

309

310

311

312

313

314

315

316

317

318

319

320

321

322

323

324

325

326

327

328

329

330

found in most areas. A large section of the sanctuary was covered by dry evergreen forests which proved to be the most suitable habitat for wild Asian elephants. This is in contrast to the Salakpra Wildlife Sanctuary, where the most suitable habitat for wild Asian elephants are mixed deciduous forests since bamboo, the elephant's favored food, is dominant in this area (Gray and Phan, 2011; Chaiyarat et al., 2015). Food-plant productivity is positively related to utilization by elephants (Rood et al., 2010) and the PKWS contains small bamboo areas. This is a primary factor affecting their movements (Lin et al., 2011) and population (Chaiyarat et al., 2015).

Previously we found that wild Asian elephants were photographed more often at salt licks, which were used for nutrient supplementation (Chaiyarat et al., 2015; Mills and Milewski, 2007) and the alleviation of gastrointestinal disorders (such as acidosis, diarrhea, and endoparasites) from plant compounds (Krishnamani and Mahaney 2000). Most salt licks were located in proximity to streams or waterholes. The principal factor determining salt lick use was the annual rainfall cycle as elephant movements are strongly controlled by water availability, especially during the dry season (de Beer and van Aarde 2008).

Our research indicates that the factors relevant to elephant populations are salt licks, elevations, land covers, and forest types. In order to effectively manage wild elephant populations, the following actions must be undertaken: maintain effective salt licks, monitor minerals in the salt licks as they will be beneficial for elephants as well as other wildlife, increase potential food sources such as grassland areas, remove invasive exotic plants and weeds, and reestablish food-plant species in disturbed areas.

Chaiyarat et al. (2019) found that the habitat model created using MaxEnt performed well compared with a random model (where the AUC was 0.5). The test AUC values were still lower compared to the training AUC values (Giovanelli et al., 2010). Thus, these two models are suitable for studying elephants' habitat suitability. The contribution of environmental factors and results of the MaxEnt jackknife test analysis revealed that the distance from salt licks contained more useful information by itself than the other factors. The next most important factors were elevation and human activity in the PKWS. Using the MaxEnt habitat model, we determined that PKWS elephants' highly and moderately suitable areas were as large as those found in the Salakphra Wildlife Sanctuary (Chaiyarat et al., 2015). Wild Asian elephants in the PKWS selected dry evergreen forests in high elevations, which was different from the habitat used by the population in the Salakphra Wildlife Sanctuary (Chaiyarat et al., 2015). However, this population did not enter agricultural areas (Table 2).

Both data sets calculated using the MCP and $\mathrm{KDE}(95 \% \mathrm{KDE}$; the total area inside PKWS $=1,554.9 \mathrm{~km}^{2}$ ) are larger than data taken at the Salakphra Wildlife Sanctuary (Youngpoy, 2012). Due to the small population (114 individuals), better food quality may have been available in higher quantities than in the larger herds. The suitable-habitat area in the PKWS was also smaller than the one in the Salakphra Wildlife Sanctuary (Chaiyarat et al., 2015). In this study, the MCP was similar to the suitable habitat area (MaxEnt) covering the entire PKWS. In Chaiyarat et al. (2019) we found that this trend indicated that an increase in this sanctuary's population may cause animals to enter agricultural areas or other protected area since both areas are suitable to support the population. 
331

332

333

334

335

336

337

338

339

340

341

342

343

344

345

346

347

348

349

350

351

352

353

354

355

356

357

358

359

360

361

362

363

364

365

366

367

368

369

370

371

In the future, conservation and management should focus on monitoring the population trends, food quality, food quantity, and the physical condition of this population to ensure the long-term conservation of this species. Regular monitoring and surveys are required to build up a comprehensive database on the population trends, improve public awareness and law enforcement, and effectively manage the habitat. These changes may help reduce the humanelephant conflict in the area.

\section{Conclusions}

Our study suggests that the wild Asian elephant population in the PKWS was lower than in other areas in Thailand and elsewhere. The resources in the sanctuary are suitable for seven herds. Wild Asian elephant populations in this sanctuary are increasing. In PKWS, wild Asian elephants are distributed according to elevation, the presence of dry evergreen forests, distance from salt licks, and human activity. However, to ensure the long-term conservation of wild Asian elephants and other Asian elephant populations effective management strategies must be used to improve habitat suitability.

\section{Acknowledgements}

We would like to thank the director and staff of the Phu Khieo Wildlife Sanctuary, Department of National Parks, Wildlife and Plant Conservation for helping us collect the data.

\section{References}

Acharya, K. P., Paudel, P. K., Neupane, P. R., \& Köhl, M. (2016). Human-wildlife conflicts in Nepal: Patterns of human fatalities and injuries caused by large mammals. PloS One, 11 (9), 1e18. https://doi.org/10.1371/journal.pone.0161717.

Aebischer, N. J., Robertson, P. A., \& Kenward, R. E. (1993). Compositional analysis of habitat use from animal radio-tracking data. Ecology, 74(5), 1313-1325.

Alfred, R., Payne, J., Williams, C., Ambu, L. N., How, P. M., \& Goossens, B. (2012). Home range and ranging behaviour of Bornean elephant (Elephas maximus borneensis) females. PLoS One, 7(2), e31400

Arivazhagan, C., \& Sukumar, R. (2008). Constructing age structures of Asian elephant populations: A comparison of two field methods of age estimation. Gajah, 29, 11-16. Burnham, K. P., Anderson, D. R. and Laake, J. K. (1980). Estimation of density from line transect sampling of biological populations. Wildlife Monographs, 72. Carbone, C., Christie, S., Conforti, K., Coulson, T., Franklin, N., Ginsberg, J. R., Griffiths, M., Holden, J., Kawanishi, K., Kinnaird, M., Laidlaw, R., Lynam, A., Macdonald, D. W., Martyr, D., McDougal, C., Nath, L., O’Brien, T., Seidensticker, J., Smith, D. J. L., Sunquist, M., Tilson, R., \& Wan Shahruddin, W. N. (2001). The use of photographic rates to estimate densities of tigers and other cryptic mammals. Animal Conservation, 4, 75-79.

Chaiyarat, R., Youngpoy, N., \& Prempree, P. (2015). Wild Asian elephant (Elephas maximus) population in Salakpra Wildlife Sanctuary, Thailand. Endangered Species Research, 29(2), 95102.

Peer] reviewing PDF | (2021:01:57278:3:0:NEW 6 Jul 2021) 
372 Chaiyarat, R., Youngpoy, N., Kongsurakan, P., \& Nakbun, S. (2019). Habitat preferences of 373 reintroduced banteng (Bos javanicus) into the Salakphra Wildlife Sanctuary, Thailand. Wildlife 374 Research, 46(7), 573-586.

375 Choudhury, A. U. (1999). Status and conservation of the Asian elephant Elephas maximus in 376 northeastern India. Mammal Reviews, 29, 141-173.

377 De Beer, Y., \& Van Aarde, R. J. (2008). Do landscape heterogeneity and water distribution explain 378 aspects of elephant home range in southern Africa's arid savannas. Journal of Arid Environments, 379 72(11), 2017-2025.

380 ESRI. (2007). ESRI_Data \& Maps 2006. New York: ESRI: New York.

381 Faculty of Forestry. (2010). Master Plan of Phu Khieo - Nam Nao Forest Complex: Basic Data.

382 Bangkok: Faculty of Forestry, Kasetsart University. (In Thai)

383 Fielding, A. H., \& Bell, J.F. (1997). A review of methods for the assessment of prediction errors in 384 conservation presence/absence models. Environmental conservation, 24(1), 38-49.

385 Flagstad, Ø., Pradhan, N. M., Kvernstuen, L. G., \& Wegge, P. (2012). Conserving small and

386

387

388

389

390

391

392

393

394

395

396

397

398

399

400

401

402

403

404

405

406

407

408

409 fragmented populations of large mammals: Non-invasive genetic sampling in an isolated population of Asian elephants in Nepal. Journal for Nature Conservation, 20(3), 181-190.

Giovanelli, J. G., de Siqueira, M. F., Haddad, C. F., \& Alexandrino, J. (2010). Modeling a spatially restricted distribution in the Neotropics: How the size of calibration area affects the performance of five presence-only methods. Ecological Modelling, 221(2), 215-224.

Goswami, V. R., Lauretta, M. V., Madhusudan, M.D., \& Karanth, K. U. (2012). Optimizing individual identification and survey effort for photographic capture-recapture sampling of species with temporally variable morphological traits. Animal Conservation, 15, 174.e183. Gray, T. N., \& Phan, C. (2011). Habitat preferences and activity patterns of the larger mammal community in Phnom Prich Wildlife Sanctuary, Cambodia. The Raffles Bulletin of Zoology, 59(2), 311-318.

Halvorsen, R., Mazzoni, S., Dirksen, J. W., Næsset, E., Gobakken, T., \& Ohlson, M. (2016). How important are choice of model selection method and spatial autocorrelation of presence data for distribution modelling by MaxEnt. Ecological modelling, 328, 108-118.

IUCN. (2020). IUCN Red List of Threatened Species, Version $2013.2 \mathrm{https} / /$ www.iucnredlist.org (Assessed 22 Nov 2020)

Joshi, R. (2009). Asian elephant's Elephas maximus behavior in the Rajaji National Park, northwest India: eight years with Asian elephant. Nature and Science of Sleep, 7, 49-77.

Katugaha, H. I.E., de Silva, M., \& Santiapillai, C. (1999). A long-term study on the dynamics of the elephant (Elephas maximus) population in Ruhuna National Park, Sri Lanka. Biological Conservation, 89(1), 51-59.

Kendall, M. G. (1938). A new measure of rank correlation. Biometrika, 30(1-2), 81-89.

Krishnamani, R., \& Mahaney, W. C. (2000). Geophagy among primates: adaptive significance and ecological consequences. Animal behaviour, 59(5), 899-915. 
410 Lin, L., Zhang, L. T., Luo, A., Wang, L., \& Zhang, L. (2011). Population dynamics, structure and 411 seasonal distribution pattern of Asian elephant (Elephas maximus) in Shangyong Protected Area, 412 Yunnan, China. Acta Theriologica Sinica, 31(3), 226-34.

413 Matawa, F., Murwira, A., \& Schmidt, K. S. (2012). Explaining elephant (Loxodonta africana) and 414 buffalo (Syncerus caffer) spatial distribution in the Zambezi Valley using maximum entropy 415 modelling. Ecological Modelling, 242, 189-197.

416 Mills, A., \& Milewski, A. (2007). Geophagy and nutrient supplementation in the Ngorongoro 417 Conservation Area, Tanzania, with particular reference to selenium, cobalt and molybdenum. 418 Journal of Zoology, 271(1), 110-118.

419 O'Brien, T. G., Kinnaird, M. F., \& Wibisono, H. T. (2003). Crouching tigers, hidden prey: Sumatran 420 tiger and prey populations in a tropical forest landscape. Animal Conservation, 6, 131-139.

421 Pearce, J. L., \& Boyce, M. S. (2006). Modelling distribution and abundance with presence only 422 data. Journal of Applied Ecology, 43(3), 405-412.

423 Phillips, S. J. (2017). A Brief Tutorial on Maxent. Available from

424 http://biodiversityinformatics.amnh.org/open_source/maxent/. (Accessed 25 Nov 2020).

425 Prakash, T. G. S. L., Indrajith, W. A. A. D. U., Aththanayaka, A. M. C. P., Karunarathna, S., Botejue, 426 M., Nijman, V., \& Henkanaththegedara, S. (2020). Illegal capture and internal trade of wild Asian 427 elephants (Elephas maximus) in Sri Lanka. Nature Conservation, 42, 51-69.

428 Ramesh, T., Sankar, K., Qureshi, Q., \& Kalle, R. (2012). Group size and population structure of 429 megaherbivores (gaur Bos gaurus and Asian elephant Elephas maximus) in a deciduous habitat of 430 Western Ghats, India. Mammal Study, 37(1), 47-54.

431 Rood, E., Ganie, A. A., \& Nijman, V. (2010). Using presence-only modelling to predict Asian 432 elephant habitat use in a tropical forest landscape: implications for conservation. Diversity and 433 Distributions, 16(6), 975-984.

434 Rowcliffe, J. M., Field, J., Turvey, S. T., \& Carbone, C. (2008). Estimating animal density using 435 camera traps without the need for individual recognition. Journal of Applied Ecology, 45(4), 436 1228-1236.

437 Seaman, D. E., Millspaugh, J. J., Kernohan, B. J., Brundige, G. C., Raedeke, K. J., \& Gitzen, R. A. 438 (1999). Effects of sample size on kernel home range estimates. The journal of wildlife 439 management, 63(2), 739-747.

440 Steinmetz, R., Chutipong, W., Seuaturien, N., \& Chirngsaard, E. (2008). Community structure of 441 large mammals in tropical montane and lowland forest in the Tenasserim-Dawna Mountains, 442 Thailand. Biotropica, 40(3), 344-353.

443 Sukmasuang, R. (2003). Ecology and population density of Asian elephant in Huai Kha Khaeng 444 Wildlife Sanctuary. Journal of Wildlife in Thailand, 11, 13-36. (In Thai)

445 Suksavate, W., Duengkae, P., \& Chaiyes, A. (2019). Quantifying landscape connectivity for wild 446 Asian elephant populations among fragmented habitats in Thailand. Global Ecology and 447 Conservation, 19, e00685.

448 Sukumar, R. (2003). The Living Elephants: Evolutionary Ecology, Behavior, and Conservation. 449 Oxford: Oxford University Press. 
450 Sukumar, R., \& Santipiallai, C. (1993). Asian elephant in Sumatra population and habitat analysis.

451 Gajah, 11, 59.

452 Swets, J. A. (1988). Measuring the accuracy of diagnostic system. Science, 240, 1285-1293.

453 Tan, W. H., Hii, A., Solana-Mena, A., Wong, E. P., Loke, V. P. W., Tan, A. S. L., Kromann-Clausen, 454 A., Hii, N., bin Pura, P. bin Tunil, M. T., Din, S. A/L., Chin, C. F. \& Campos-Arceizet, A. (2021).

455 Long-term monitoring of seed dispersal by Asian elephants in a Sundaland rainforest. Biotropica, 456 doi.org/10.1111/btp.12889.

457 van de Water, A., \& Matteson, K. (2018). Human-elephant conflict in western Thailand: Socio-

458 economic drivers and potential mitigation strategies. PLoS ONE 13(6): e0194736.

459 Varma, S. (2011). Estimating Population Density of Large Mammals: Further Evaluation of 460 Different Methods in Mudumalai Wildlife Sanctuary, India. In: Warren, R. J., Okarma, H., \& 461 Sievert, P. R. (eds.). Wildlife, Land and People: Priorities for the 21st Century, The Wildlife 462 Society, Bethesda, Maryland, pp. 301-304.

463 Varma, S, Baskaran, N., \& Sukumar, R. (2012). Field Key for Elephant Population Estimation and 464 Age and Sex Classification: Resource material for synchronized elephant population count using 465 block count, line transect dung count method and waterhole count. Asian Nature Conservation 466 Foundation, Innovation Centre, Indian Institute of Science, Bangalore.

467 Varma, S., Pittet, A., \& Jamadagni, H. S. (2006). Experimenting usage of camera-traps for 468 population dynamics study of the Asian elephant Elephas maximus in southern India. Current 469 Science, 91(3), 324-331.

470 Vidya, T., Prasad, D., \& Ghosh, A. (2014). Individual identification in Asian elephants. Gajah, 40, 471 3-17.

472 Vigne, L. (2013). Recent findings on the ivory and rhino-horn trade in Lao People's Democratic 473 Republic. Pachyderm, 54, 36-44.

474 Wall, J., Douglas-Hamilton, I., \& Vollrath, F. (2006). Elephants avoid costly mountaineering. 475 Current Biology, 16(14), R527-R529.

476 Wanghongsa, S., Boonkird, K., Saensen, D., \& Jantarat, N. (2007). Monitoring of Elephant 477 Population in Khao Ang Rue Nai Wildlife Sanctuary. Bangkok: Report of the Forest and Plant 478 Conservation Research Office, Department of National Parks, Plant Conservation, pp. 398-412.

479 Wanghongsa, S., Senatham, Y., Boonkird, K., \& Saengsen, D. (2006). Why do elephant bulls 480 wander outside forest areas of Khao Ang Rue Nai Wildlife Sanctuary? Wildlife Yearbook, 7, 481 156-169.

482 Williams, C., Tiwari, S. K., Goswami, V. R., de Silva, S., Kumar, A., Baskaran, N., Yoganand, K. 483 \& Menon, V. 2020. Elephas maximus. The IUCN Red List of Threatened Species 2020:

484 e.T7140A45818198. https://dx.doi.org/10.2305/IUCN.UK.2020-3.RLTS.T7140A45818198.en. 485 Wilson, G., Gray, R. J., Radinal, R., Hasanuddin, H., Azmi, W., Sayuti, A., Muhammad, H., 486 Abdullah, A., Nazamuddin, B. S., Sofyan, H., Riddle, H. S., Stremme, C. \& Desai, A. A. (2021). 487 Between a rock and a hard place: Rugged terrain features and human disturbance affect 488 behaviour and habitat use of Sumatran elephants in Aceh, Sumatra, Indonesia. Biodiversity 489 Conservation, doi.org/10.1007/s10531-020-02105-3. 
490 Youngpoy, N. (2012). Population and activities of wild elephants (Elephas maximus) in Salakphra 491 Wildlife Sanctuary, Kanchanaburi Province, Thailand. Nakorn Pathom: M.Sc. Thesis, Mahidol 492 University. 


\section{Table $\mathbf{1}$ (on next page)}

Kendall's rank correlation coefficients between pairs of environmental factors in the Phu Khieo Wildlife Sanctuary.

Note The $\tau$ value is always between -1 and $1 ; \tau=1=$ Perfect (very strong) positive correlation; $\tau=-1=$ Perfect (very strong) negative correlation; $\tau=0=$ zero (no) correlation; **correlation is significant at the 0.001 level (2-tailed); *correlation is significant at the 0.05 level (2-tailed); villages, roads, and streams were combined as "Human Activity" in the distribution maps. 
1 Table 1 Kendall's rank correlation coefficients between pairs of environmental factors in the $2 \quad$ Phu Khieo Wildlife Sanctuary.

\begin{tabular}{|c|c|c|c|c|c|}
\hline Salt lick & & & & & \\
\hline 0.070 & Station & & & & \\
\hline-0.035 & $0.192 * *$ & Stream & & & \\
\hline$-0.110 *$ & $0.469 * *$ & $-0.193 * *$ & Village & & \\
\hline 1.000 & 0.070 & -0.035 & $-0.110^{*}$ & Road & \\
\hline 0.089 & $0.412 * *$ & $-0.211 * *$ & $0.669 * *$ & 0.089 & Elevation \\
\hline $0.229 * *$ & -0.093 & -0.039 & $-0.155^{*}$ & $0.229 * *$ & -0.025 \\
\hline
\end{tabular}

3 Note The $\tau$ value is always between -1 and $1 ; \tau=1=$ Perfect (very strong) positive correlation; $\tau=-1=$ 4 Perfect (very strong) negative correlation; $\tau=0=$ zero (no) correlation; **correlation is significant at the 50.001 level (2-tailed); *correlation is significant at the 0.05 level (2-tailed); villages, roads, and streams 6 were combined as "Human Activity" in the distribution maps. 


\section{Table 2 (on next page)}

Relative frequency (RF), relative abundance index (RAI), and the environmental factors affecting elephants in camera trap stations in the Phu Khieo Wildlife Sanctuary between 2016 and 2019. 
1 Table 2 Relative frequency (RF), relative abundance index (RAI), and the environmental factors 2 affecting elephants in camera trap stations in the Phu Khieo Wildlife Sanctuary between 3 2016 and 2019.

\begin{tabular}{llllll}
\hline Environmental Factor & Present & & $\begin{array}{l}\text { Trap-Night } \\
\text { (Nights) }\end{array}$ & $\begin{array}{l}\text { Encounter } \\
\text { Rate }\end{array}$ & RAI \\
\cline { 2 - 4 } Number & $\%$ & 100 & 6,896 & 4,319 & 62.6 \\
\hline Total Camera Trap Station & 149 & 32.9 & & & \\
Relative Frequency (RF) & 49 & & & & \\
Forest & & 83.7 & & \\
$\quad$ Dry Evergreen Forest & 41 & 14.3 & & \\
$\quad$ Mixed Deciduous Forest & 7 & 0 & & \\
$\quad$ Pine Forest & 0 & 2 & & \\
Dry Dipterocarp Forest & 1 & 0 & & \\
Secondary Forest & 0 & 100 & & \\
Total & 49 & & & \\
Elevation (m) & & 4.1 & & \\
$200-400$ & 2 & 10.2 & & \\
$400-700$ & 5 & 59.2 & & \\
$700-900$ & 29 & 14.3 & & \\
$900-1,100$ & 7 & 12.2 & & \\
$1,100-1,300$ & 6 & 100 & & \\
Total & 49 & & & \\
Slope (\%) & & 55.1 & & \\
0 - 20 & 27 & 20.4 & & \\
$20-40$ & 10 & 16.3 & & \\
$40-60$ & 4 & 8.2 & & \\
$60-80$ & 49 & 100 & & \\
Total & & & & \\
\hline
\end{tabular}

4 


\section{Table 3 (on next page)}

Population structure and sex ratio of wild elephants in the Phu Khieo Wildlife Sanctuary between 2016 and 2019.

$F=1.072 ; d f=5 ; P$-value $=0.382 ; \mathrm{A}=$ Duncan test for sex ratio; $\mathrm{B}=$ Duncan test for reproductive ratio; $\mathrm{N} / \mathrm{A}=$ not analyzed. 
1 Table 3 Population structure and sex ratio of wild elephants in the Phu Khieo Wildlife Sanctuary $2 \quad$ between 2016 and 2019.

\begin{tabular}{|c|c|c|c|c|c|c|c|c|c|c|c|c|}
\hline \multirow[t]{2}{*}{ Herd } & \multirow[t]{2}{*}{$\begin{array}{l}\text { Elephant } \\
\text { (Individuals) }\end{array}$} & \multicolumn{6}{|c|}{ Individuals (Sex Ratio) } & \multirow[t]{2}{*}{ A } & \multicolumn{3}{|c|}{$\begin{array}{l}\text { Reproductive } \\
\text { Ratio }\end{array}$} & \multirow[t]{2}{*}{ B } \\
\hline & & $\mathrm{AM}$ & $\mathrm{AF}$ & SM & SF & $\mathrm{JU}$ & CL & & $\mathrm{AF}$ & $\mathrm{JU}$ & $\mathrm{CA}$ & \\
\hline 1 & 12 & 2(1) & $6(3)$ & 0 & $2(0.3)$ & $2(0.3)$ & 0 & 2.67 & 1 & 0.3 & 0 & 2.67 \\
\hline 2 & 22 & $3(1)$ & $10(3.3)$ & $5(0.5)$ & $2(0.2)$ & $2(0.2)$ & 0 & 2.55 & 1 & 0.2 & 0 & 2.55 \\
\hline 3 & 25 & $6(1)$ & $10(1.7)$ & $3(0.3)$ & $2(0.2)$ & $2(0.2)$ & $2(0.2)$ & 2.6 & 1 & 0.2 & 0.2 & 2.6 \\
\hline 4 & 13 & $2(1)$ & $5(2.5)$ & $2(0.4)$ & $1(0.2)$ & $3(0.6)$ & 0 & N/A & 1 & 0.6 & 0 & 2.75 \\
\hline 5 & 12 & $4(1)$ & $6(1.5)$ & 0 & $1(0.2)$ & 0 & $1(0.2)$ & 1.6 & 1 & 0 & 0.2 & N/A \\
\hline 6 & 14 & $3(1)$ & $4(1.3)$ & $4(1)$ & $1(0.3)$ & 0 & $2(0.5)$ & 2.54 & 1 & 0 & 0.5 & 2.54 \\
\hline 7 & 8 & 2(1) & 2(1) & 0 & 0 & $2(1)$ & $2(1)$ & N/A & 1 & 1 & 1 & N/A \\
\hline Total & 114 & $30(1)$ & $43(1.4)$ & $14(0.5)$ & $9(0.3)$ & $11(0.4)$ & $7(0.2)$ & N/A & 1 & 0.3 & 0.2 & N/A \\
\hline
\end{tabular}

$3 \quad F=1.072 ; d f=5 ; P$-value $=0.382 ; \mathrm{A}=$ Duncan test for sex ratio; $\mathrm{B}=$ Duncan test for reproductive 4 ratio; $\mathrm{N} / \mathrm{A}=$ not analyzed. 
Table 4 (on next page)

Estimated relative contributions of environmental variables, overall prevalence of training AUC, test gain, and test AUC of the MaxEnt model. 
1 Table 4 Estimated relative contributions of environmental variables, overall prevalence of 2 training AUC, test gain, and test AUC of the MaxEnt model.

\begin{tabular}{llll}
\hline Environmental & Percentage of Contribution (\%) & Permutation Importance (\%) & \\
Variable & & & \\
\hline Saltlick & 14.9 & 36.4 & \\
Elevation & 52 & 23.5 & \\
Human Activity & 9.8 & 20.2 & \\
Forest & 23.2 & 19.2 & Test \\
Slope & 0.1 & 0.6 & AUC \\
Model & Training AUC & Test Gain & 0.494 \\
& & & 0.393 \\
0 & 0.69 & -0.14 & 0.41 \\
1 & 0.731 & -1.211 & 0.731 \\
2 & 0.704 & -0.277 & 0.819 \\
3 & 0.67 & 0.227 & 0.667 \\
4 & 0.675 & 0.414 & 0.59 \\
5 & 0.681 & 0.131 & 0.566 \\
6 & 0.697 & 0.047 & 0.629 \\
7 & 0.686 & 0.007 & 0.59 \\
8 & 0.69 & 0.111 & 0.814 \\
9 & 0.694 & 0.048 & 0.519 \\
10 & 0.678 & 0.302 & 0.76 \\
11 & 0.695 & -0.033 & 0.543 \\
12 & 0.677 & 0.233 & 0.619 \\
13 & 0.692 & -0.046 & 0.61 \\
14 & 0.679 & 0.077 &
\end{tabular}

3 


\section{Table 5 (on next page)}

Suitable area (MaxEnt) and home range of wild Asian elephant herds with Minimum Convex Polygon (95\% MCP) and Kernel Density Estimate (KDE) in the Phu Khieo wildlife Sanctuary between 2016 and 2019.

Note: Habitat suitability area ranged from 0 to 1: Most suitable $=$ most optimal habitat for wild Asian elephants $=>0.66$ to 1 , Moderate suitable $=$ moderately optimal habitat for wild Asian elephants $=>0.33$ to 0.66 , Lowest suitable $=$ suboptimal habitat for wild Asian elephants $=>0$ to $0.33 ; \mathrm{N} / \mathrm{A}=$ not analyzed. 
1 Table 5 Suitable area (MaxEnt) and home range of wild Asian elephant herds with Minimum Convex Polygon (95\% MCP) and Kernel Density Estimate (KDE) in the Phu Khieo wildlife Sanctuary between 2016 and 2019.

\begin{tabular}{|c|c|c|c|c|c|c|c|c|c|}
\hline \multirow[t]{2}{*}{ Population habitat use } & \multicolumn{7}{|c|}{ Herd No. $\left(\mathrm{km}^{2}\right)$} & \multicolumn{2}{|c|}{ All Herd $\left(\mathrm{km}^{2}\right)$} \\
\hline & 1 & 2 & 3 & 4 & 5 & 6 & 7 & $\begin{array}{l}\text { Total } \\
\text { area }\end{array}$ & $\begin{array}{l}\text { Inside } \\
\text { PKWS }\end{array}$ \\
\hline Suitable area (MaxEnt) & 13.5 & 67.5 & 72 & 18 & 13.5 & 18 & 4.5 & $1,288.9$ & $\mathrm{~N} / \mathrm{A}$ \\
\hline Most suitable & 2.2 & 10.4 & 7.3 & 2 & 9.9 & 9.8 & 4.5 & 672.3 & N/A \\
\hline Moderate suitable & 11.3 & 57.1 & 64.7 & 16 & 3.6 & 2.5 & 0 & 616.6 & N/A \\
\hline Lowest suitable & 0 & 0 & 0 & 0 & 0 & 5.8 & 0 & 276.9 & $\mathrm{~N} / \mathrm{A}$ \\
\hline \multicolumn{10}{|l|}{ Forest type } \\
\hline Hill evergreen forest & & & & & & & & & $\mathrm{N} / \mathrm{A}$ \\
\hline Mixed deciduous forest & & & & & & & & & $\mathrm{N} / \mathrm{A}$ \\
\hline $\mathrm{MCP}(95 \%)$ & 13.5 & 67.5 & 72 & 18 & 13.5 & 18 & 4.5 & 1,098 & $\mathrm{~N} / \mathrm{A}$ \\
\hline Forest type & & & & & & & & & $\mathrm{N} / \mathrm{A}$ \\
\hline Hill evergreen forest & & & & & & & & & N/A \\
\hline Mixed deciduous forest & & & & & & & & & N/A \\
\hline \multicolumn{10}{|l|}{ KDE } \\
\hline $95 \%$ & 58.9 & 118.2 & 100.1 & 69.9 & 127.1 & 65.9 & $\mathrm{~N} / \mathrm{A}$ & $3,131.9$ & $1,554.9$ \\
\hline $90 \%$ & 53.0 & 106.5 & 90.6 & 62.2 & 114.2 & 59.3 & $\mathrm{~N} / \mathrm{A}$ & $2,522.7$ & $1,535.2$ \\
\hline $50 \%$ & 33.7 & 68.8 & 59.1 & 38.9 & 70.9 & 38.6 & $\mathrm{~N} / \mathrm{A}$ & $8,70.3$ & 826.5 \\
\hline \multicolumn{10}{|l|}{ Forest type with $95 \%$} \\
\hline \multicolumn{10}{|l|}{ KED } \\
\hline Hill evergreen forest & & & & & & & & & $\mathrm{N} / \mathrm{A}$ \\
\hline Mixed deciduous forest & & & & & & & & & N/A \\
\hline
\end{tabular}

4 Note: Habitat suitability area ranged from 0 to 1: Most suitable $=$ most optimal habitat for wild Asian elephants $=>0.66$ to 1 , Moderate suitable $=$ moderately optimal habitat for wild Asian elephants $=>0.33$ to 0.66 , Lowest suitable $=$ suboptimal habitat for wild Asian $7 \quad$ elephants $=>0$ to $0.33 ; \mathrm{N} / \mathrm{A}=$ not analyzed. 
Figure 1

Location of the Phu Khieo Wildlife Sanctuary, Thailand. 


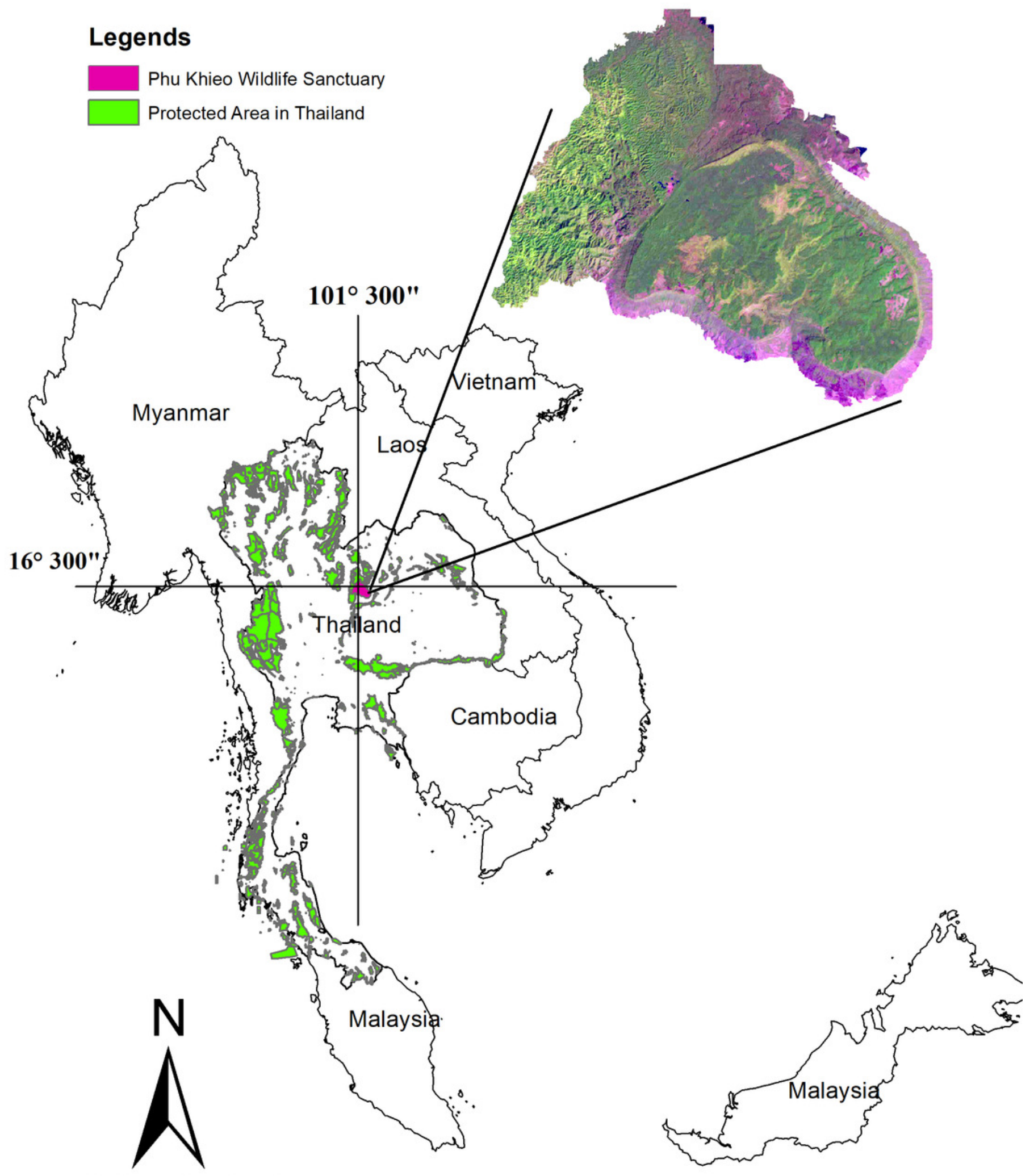

$\begin{array}{lllll}0 & 80160 & 320 & 480 & 640\end{array}$ Kilometers 
Figure 2

Environmental factors used to create the distribution model of wild Asian elephants with median grids in the Phu Khieo Wildlife Sanctuary, Thailand.

(A) Forest types. (B) Slope. (C) Elevation. (D) Human activity (villages, roads, wildlife stations, and streams). (E) Salt licks. 

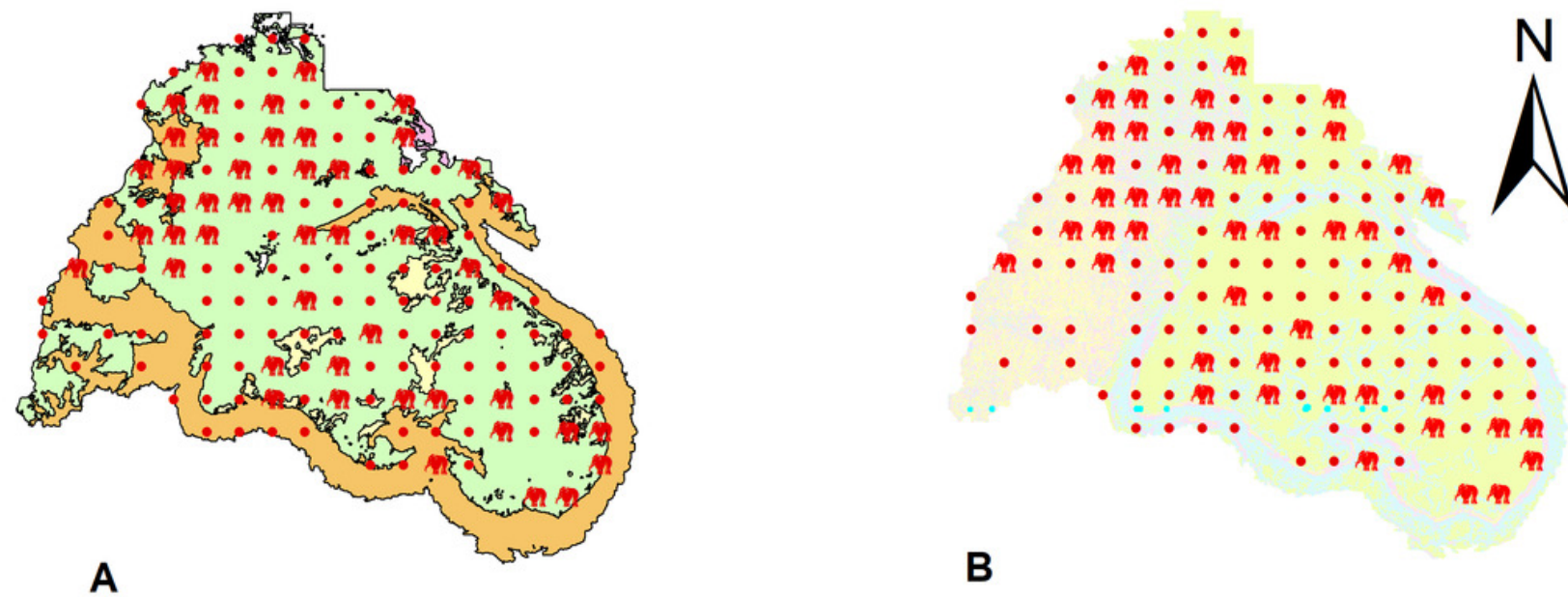

B

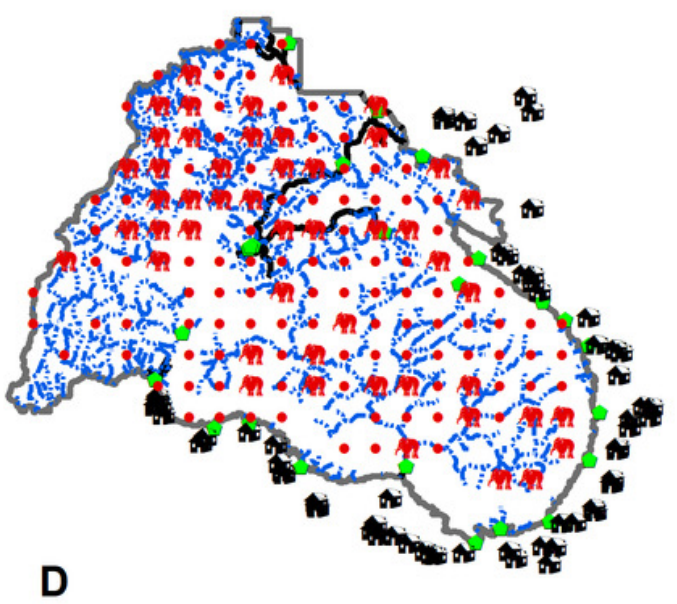

\section{Legends}
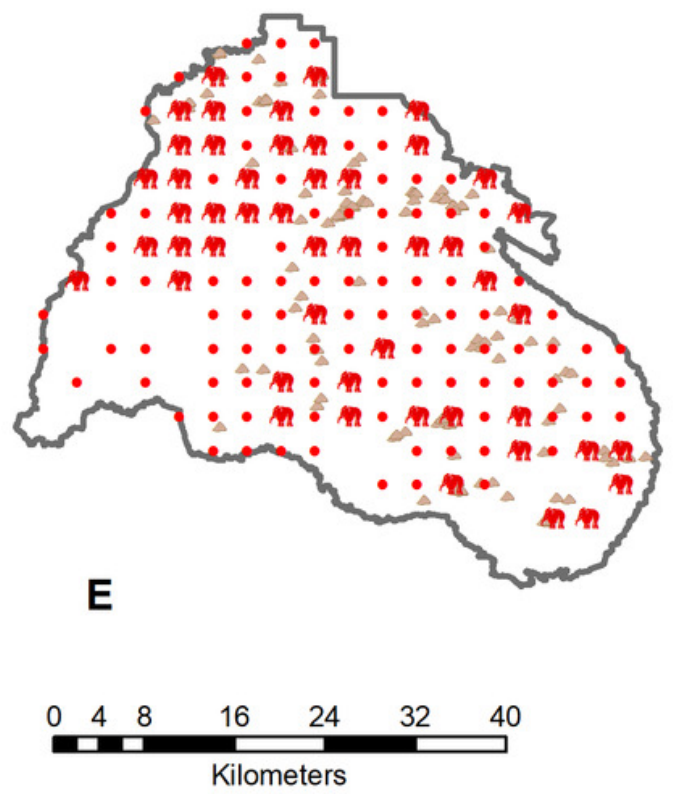

149 Camera Trap Locations

Slopes (\%)

An Elephant photography locations $10-20$

- Salt licks

$20-40$

Villages

$40-60$

$60-80$

Elevations (m)

Road

Hill Evergreen Forest

Mixed Deciduous Forest

$200-400$

$400-700$

$700-900$

$900-1100$

$1100-1300$

Dry Dipterocarp Forest

Secondary Forest 
Figure 3

Population habitat use of each wild Asian elephant herd in the PKWS between 2016 and 2019 using MCP and KDE.

Herd $1(A)$, herd $2(B)$, herd $3(C)$, herd $4(D)$, herd $5(E)$, herd $6(F)$, and herd $7(G)$. 

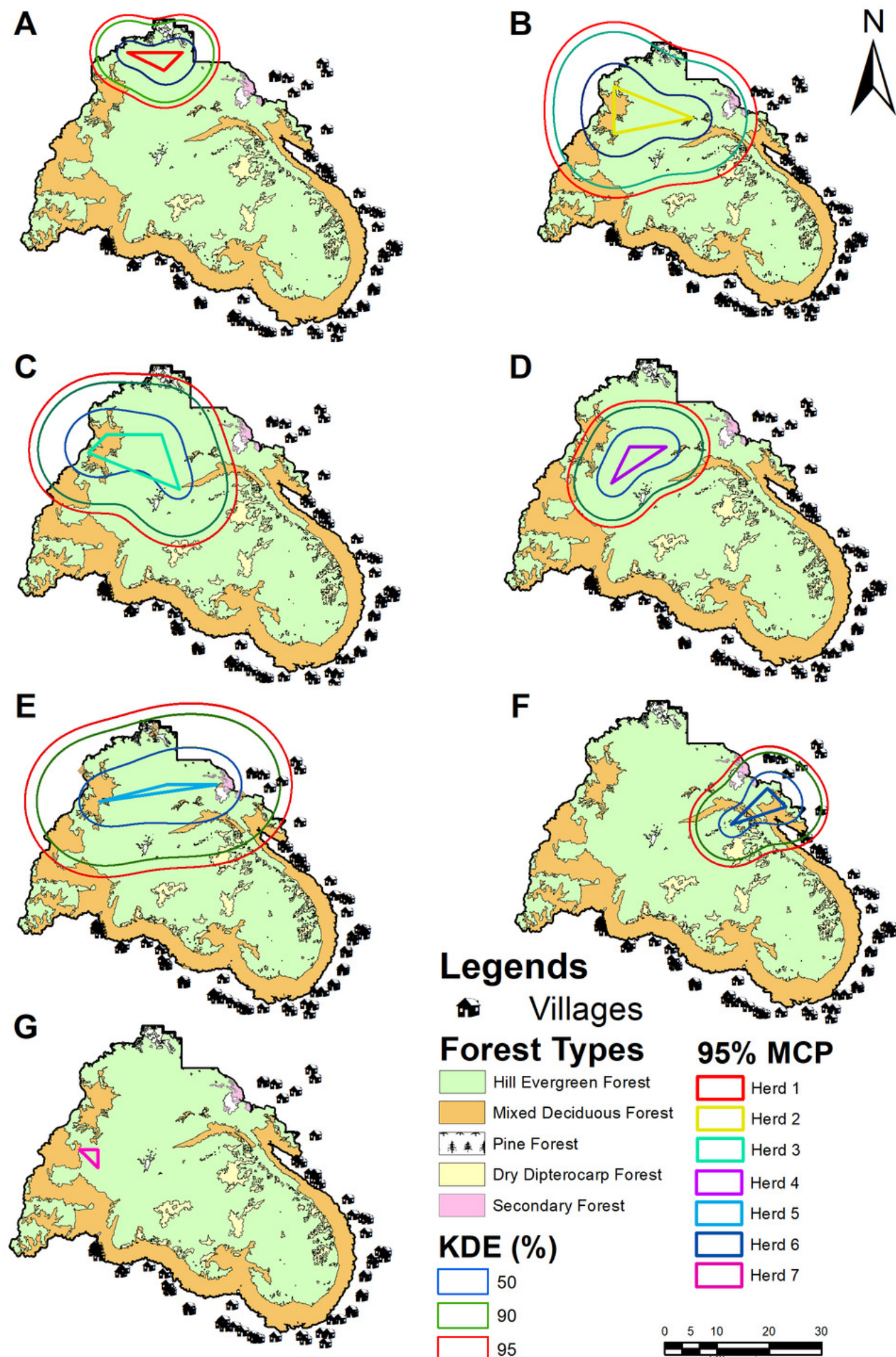

\section{Legends}
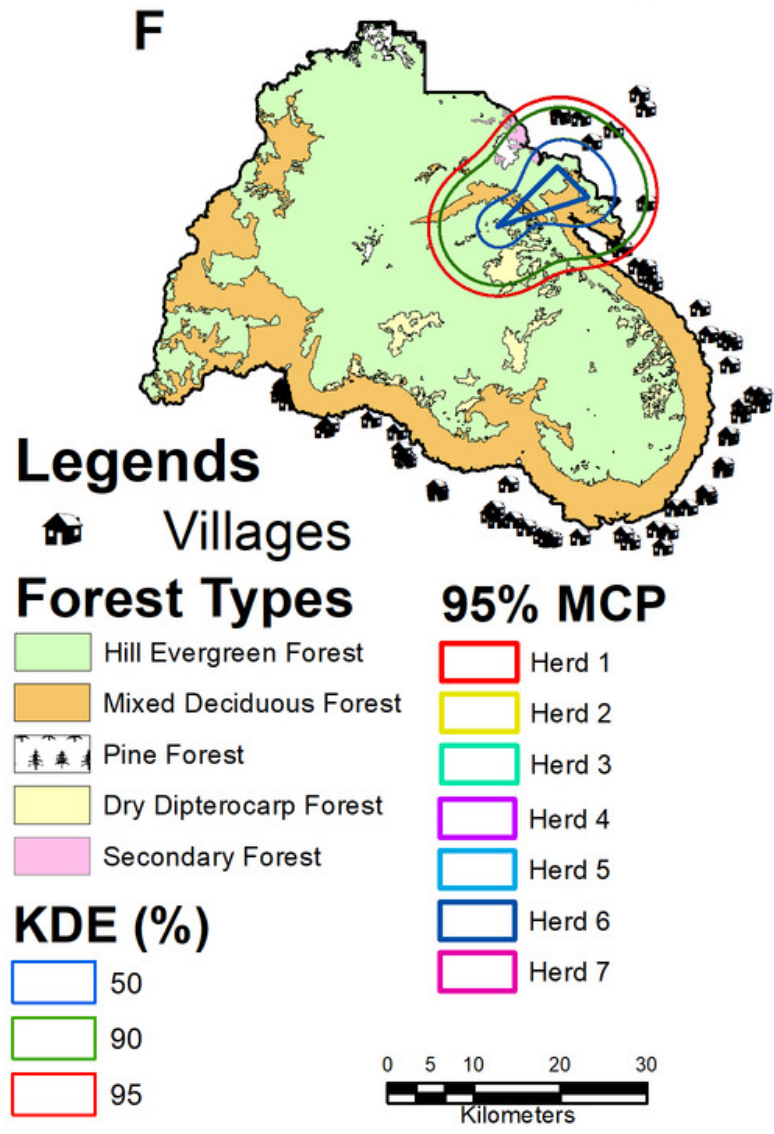
Figure 4

Distribution model of wild Asian elephants with median grids in the Phu Khieo Wildlife Sanctuary, Thailand. 


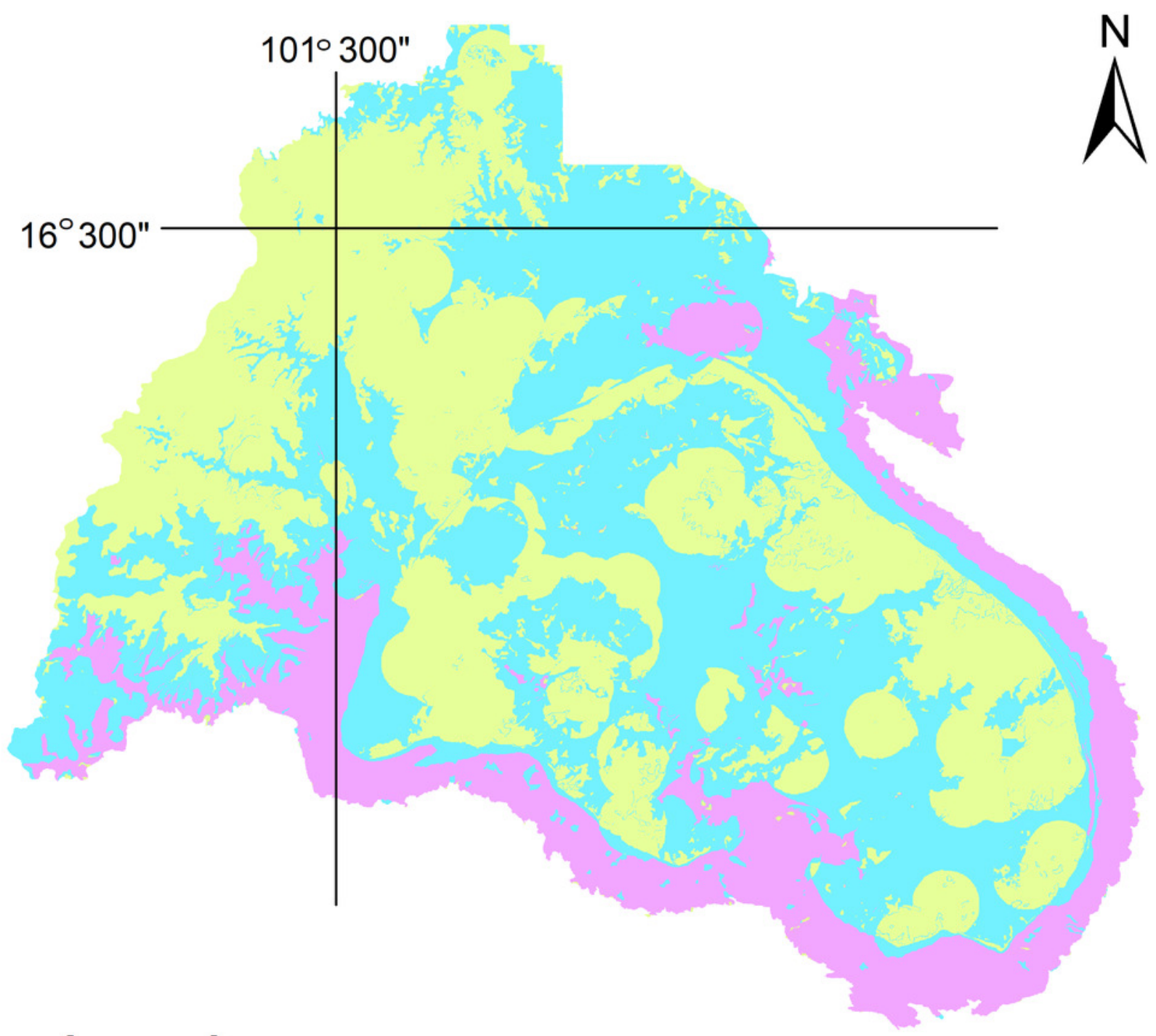

Legends

\section{Habitat Selection Area}

\section{Area}

Most suitable

Moderate suitable

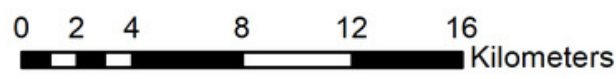

Lowest suitable 


\section{Figure 5}

Test omission rate and predicted area curves as a function of the cumulative threshold.

Average over the replicate runs (A), curve of the receiver operating characteristic (ROC) plot with evenly spaced thresholds and area under the ROC (AUC) for our habitat suitability model using MaxEnt (B), the average test AUC for the replicate runs is $0.61 \pm 0.13$ (mean $\pm S D$ ) and results of the jackknife test for contributions of the variables of the wild Asian elephant habitat model in Phu Khieo Wildlife Sanctuary, Thailand (C). Distance from each land used and land cover (LC) is given in $m$, elevation is given in $m$, forest is distance from forest ( $m$ ), saltlick is distance from salt lick ( $\mathrm{m})$, and slope is the percentage of slope (\%).

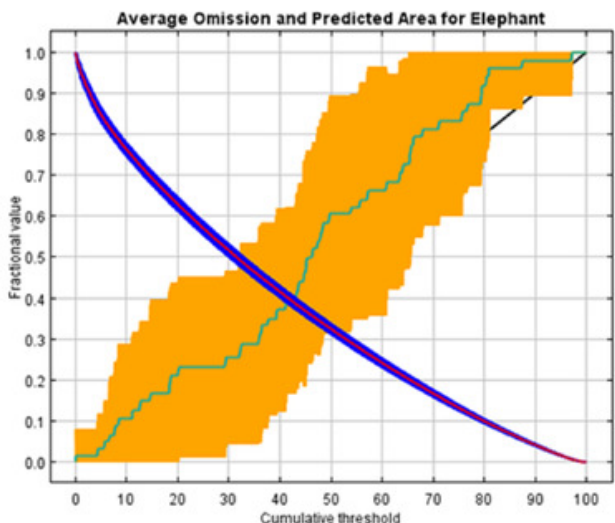

A
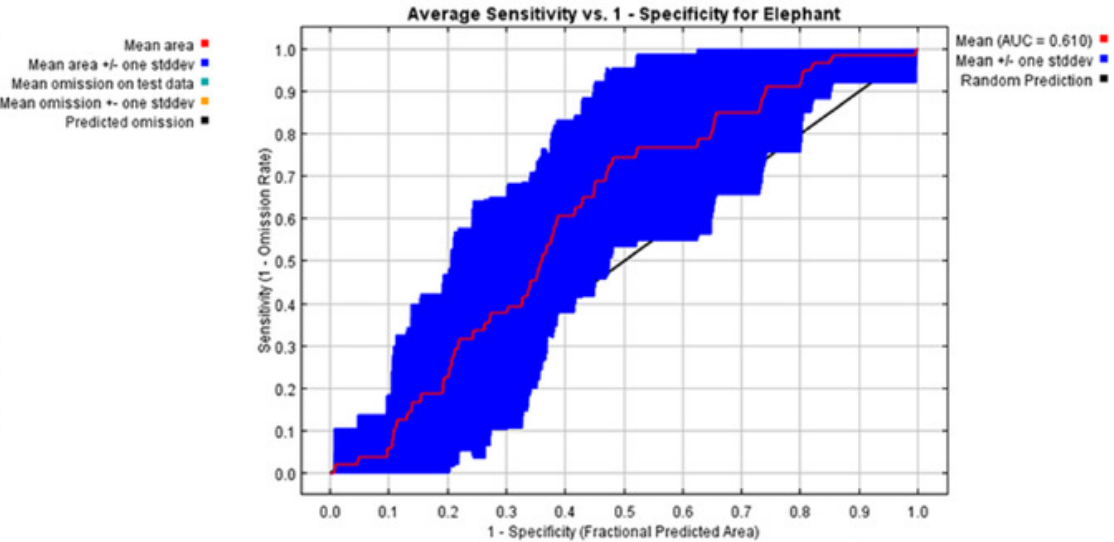

B

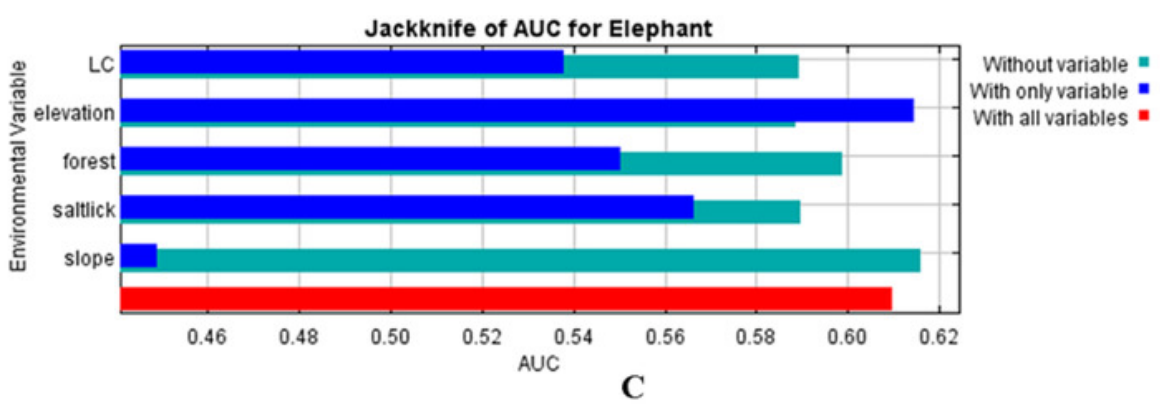


Figure 6

Wild Asian elephant populations' habitat use in the Phu Khieo Wildlife Sanctuary between 2016 and 2019. Habitat use was determined with the MCP and KDE. 


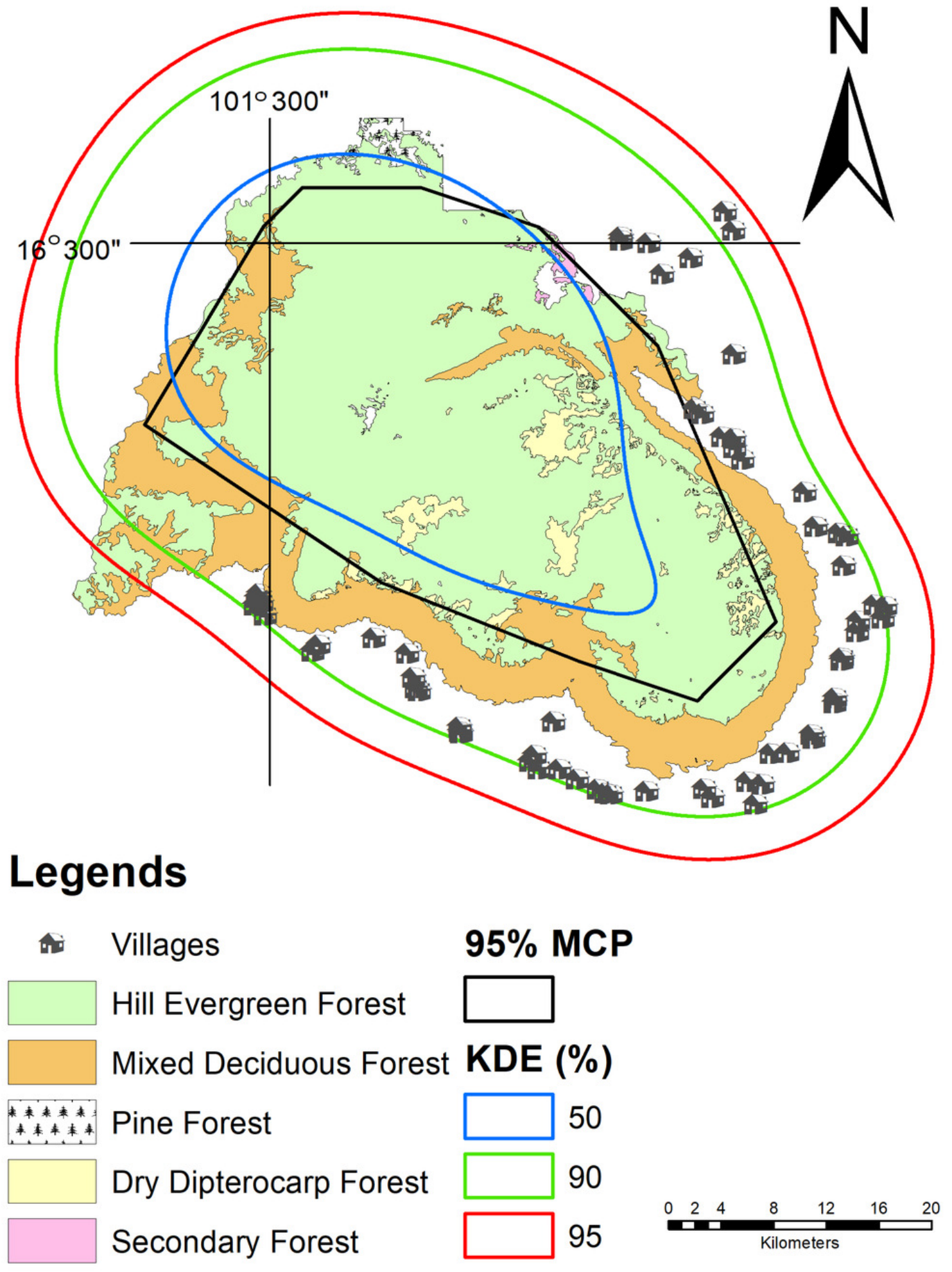

